\title{
Study of Characteristics of Fault in Overhead and Underground Cable Distribution System Using Experimental Test Bench
}

\author{
Piladelak Yindeesap ${ }^{\text {a }}$ and Atthapol Ngaopitakkul ${ }^{\mathrm{a},{ }^{*}}$ and Monthon Leelajindakrairerk ${ }^{\mathrm{a}}$ \\ ${ }^{a}$ Faculty of Engineering, King Mongkut's Institute of Technology Ladkrabang, \\ Chalongkrung Road,Ladkrabang, Bangkok 10520, Thailand. \\ *E-mail: knatthap@kmitl.ac.th
}

\begin{abstract}
This paper is focused on the behavior of current waveform when the single line to ground fault occurs on the pilumped equivalent circuit experimental test bench of distribution system. The experimental test bench can be divided into the distribution system either overhead line or underground cable. The parameter of experimental test bench is calculated based on per-unit method by using the data from the $115 \mathrm{kV}$ distribution system in Thailand. The various case studies are performed by changing the type of distribution system, the location of fault, the inception angle of fault including varying the load. The obtained results show that, during the fault occurrence, the current waveform has a sudden change and increases more than 10 times in comparison with normal condition. Finally, the results from the experimental test bench will be beneficial in the behavioral study of the fault current in case of both overhead line and underground cable and will be development of the short-circuit protection system in the distribution system.
\end{abstract}

Keywords-Short circuit; Distribution system; Experiment setup; Overhead line; Underground cable; Fault

\section{INTRODUCTION}

Presently, distribution system is one of important parts in power system, which sends electrical energy from utility to end user. Generally, the distribution system can be divided into several voltage levels, but has still used the conductor either overhead line or underground cable. When disturbance (or fault) occurs in distribution system, a serious problem can be caused for the end user such as black out or damage to sensitive equipment, so this distribution system must have reliability and stability. The failure occurring in distribution system and affecting to the end user system must be detected and rejected from the system.

Nowadays, the characteristics of power system have been studied using simulation program [1-6] or mathematical model [7-8]. By considering the literature review about simulation program, this research studies the fault location in transmission line of 3-phase multi-generator system in conjunction with an adaptive neuro-fuzzy inference system (ANFIS) and artificial neural network (ANN) [1]. In [2], the incipient fault was detected in underground cable and compared detection's result with the superimposed components-based scheme [2]. The PSS/E program was used for analyzing power transfer capability and dynamic stability of the power system when subjected to small disturbances [3]. In [4], the disturbance analysis from simulation model is simulated by both wavelet analysis and PSS/E program. In addition, the simulation program such as PSS/E, EMTP-ATP and PSCAD/EMTDC are used to study the power system with mathematical model. In [5], by simulation using EMTPATP model, the saturation of transformer can cause the fault in transmission line. In [6], by simulation using PSCAD/EMTDC program, this research proposed techniques to distinguish the transient origine among the faults, the normal switching, and the capacitor bank switching [6]. By considering the literature review about mathematical model, fuzzy and neural network are interesting to study the path characteristic frequency-based fault for locating single line to ground fault in radial distribution systems. The neural networks with genetic algorithm (GAs) and fuzzy theory were studied to verify voltage sag, which caused fault in the system [8]. As a result, these research papers show advantage as convenient and efficient program for simulating complex system to analyse result. However, the simulation program and mathematic model cannot show some of desired functions as noise or other disturbances, which are created by nature.

In this paper, the characteristics of the fault current waveforms were studied and analysed from the experimental test bench of distribution system. The overhead line and underground cable with pi-lumped equivalent circuit can be simulated using this experimental test bench. The fault current in case of single line to ground fault was investigated to study and understand the characteristics of fault when fault occurs either in overhead line or underground cable distribution system. In addition, the various case studies are performed by changing the type of distribution system, the location of fault, the inception angle of fault including varying the load.

\section{EXPERIMENTAL TEST BENCH}

The Thailand's $115 \mathrm{kV}$ distribution system (Bangsaotong-muangmai substation) is considered as distribution model as shown in Figure 1. By considering the Figure 1(a), this experimental test bench can be adjusted the 
distribution model as either overhead line or underground cable. For design of this experimental test bench as shown in Figure 1(b), the pi-lumped equivalent circuit is used to a distribution system model which consists of series inductor and shunt capacitor while the resistance of conductor is ignored. The parameter of experimental test bench employing the data from the $115 \mathrm{kV}$ distribution system in Thailand is calculated using geographic information system data, the lengths of the distribution system, the size of conductor, and span of pole or pipe, and then normalized based on per-unit method in order to transform parameter from voltage level of $115 \mathrm{kV}$ to laboratory voltage level of $220 \mathrm{~V}$. By considering the Figure 1(b) and Figure 2, this pilumped equivalent circuit is divided into 2 parts in order to install the zero cross circuit and the magnetic contactor.

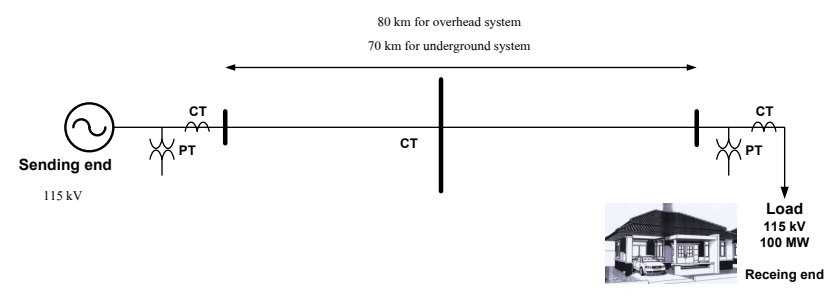

(a) the real distribution system used as distribution model.

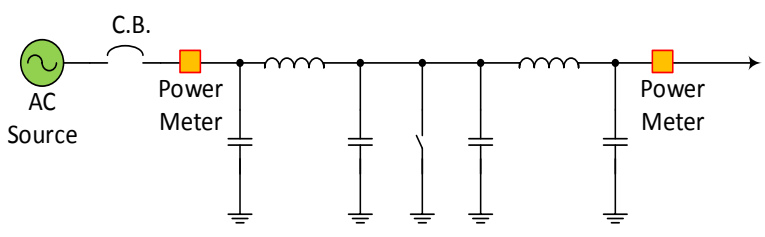

(b) pi-lumped equivalent model.

Fig. 1. one-line diagram for distribution system.

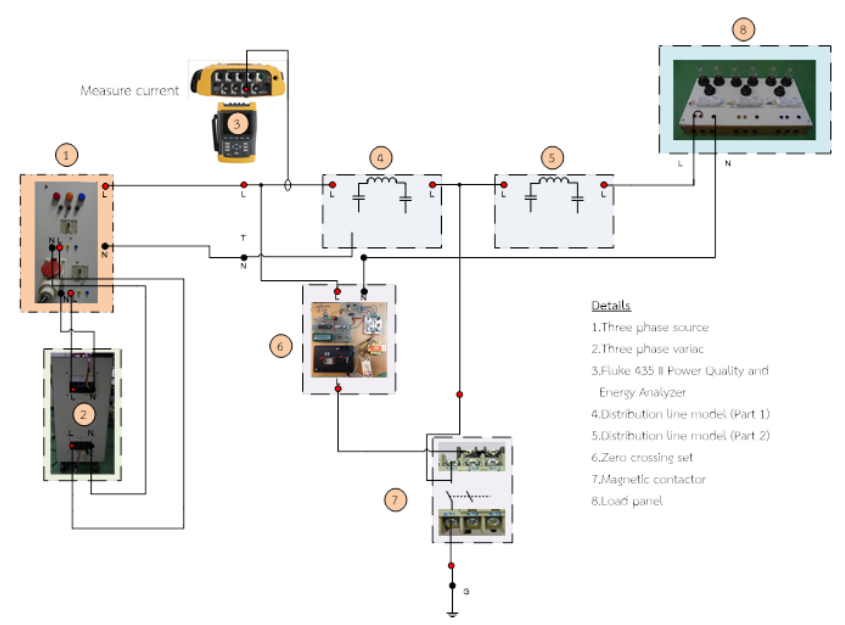

Fig. 2. Overall single-line diagram of experimental test bench.
By considering the Figure 2, the variable voltage transformer was used as power supply for the experimental test bench. For protecting the experimental test bench, the circuit breaker with $30 \mathrm{~A}$ and fuses were used to protect the variable voltage transformer. For controlling the short-circuit (or fault) of experimental test bench, the zero crossing circuit was used to determine the inception angle of fault including sending signal to magnetic contactor for implementing the short-circuit. For measurement, the energy meter (Fluke 435II) was used in order to measure the amplitude of current including capture the current waveform using current probe.

To study the characteristics of fault current when the single-line to ground fault occurs on the experimental test bench, the various case studies were performed with following changes of the parameters:

- $\quad$ Types of distribution system are overhead line and underground cable.

- Inception angles on a phase A current waveform are varied as $90^{\circ}$, and $180^{\circ}$.

- $\quad$ Sizes of load are varied as linear load (25 W, 50 $\mathrm{W}$ ), and non-linear load (combined between $25 \mathrm{~W}$ and ballast).

- Locations of fault on each distribution system are the distance of $40 \%, 50 \%$, and $60 \%$, measured from the variable voltage transformer.

\section{RESULT AND DISCUSSION}

The fault current of each case study obtained from the experimental test bench was shown in this section. The remainder of this section is organized as follows: Section 3.1 presents the obtained current waveform in case of overhead line distribution system while in case of underground cable is shown in Section 3.2.

\subsection{Overhead line distribution system}

In this section, the case studies of experimental test bench were performed to study the characteristics of fault current during the single-line to ground fault occurrence when the fault inception angle, size of load, and fault location were changed.

By changing the inception angle of fault as shown in Table 1 and Figure 3, when fault occurs at the length of $40 \%$ measured from the variable voltage transformer for the load of $25 \mathrm{~W}$, it can be seen that, before the fault occurrence (or pre-fault condition), the maximum amplitude of current is 0.145 A. During the fault occurrence (or post-fault condition) in case of the inception angle as $90^{\circ}$, the maximum amplitude of current changes suddenly on the waveform and the maximum amplitude of current is 2.625 A. For the other inception angle of fault as shown in Figure 3(b), it can be seen that the maximum amplitude of current during fault occurrence has a value more than in case of the inception angle as $90^{\circ}$ while, during the pre-fault condition, the maximum amplitude of current was the same value as in case of the inception angle as $90^{\circ}$ as shown in Table 1 . 
Table 1. The maximum amplitude of current during pre-and post-fault condition for various inception angles of fault in overhead line distribution system.

\begin{tabular}{|c|c|c|c|c|}
\hline \multirow{2}{*}{$\begin{array}{c}\text { Location of Fault } \\
\text { (\%length of } \\
\text { distribution system) }\end{array}$} & \multirow{2}{*}{$\begin{array}{c}\text { Inception } \\
\text { angle }\end{array}$} & Size of load & \multicolumn{2}{|c|}{$\begin{array}{c}\text { Maximum amplitude of } \\
\text { current (A) }\end{array}$} \\
\cline { 4 - 5 } & & & Pre-fault & Post-fault \\
\hline \multirow{2}{*}{40} & $90^{\circ}$ & 25 & 0.145 & 2.625 \\
\cline { 3 - 5 } & $180^{\circ}$ & 25 & 0.145 & 5.203 \\
\hline
\end{tabular}

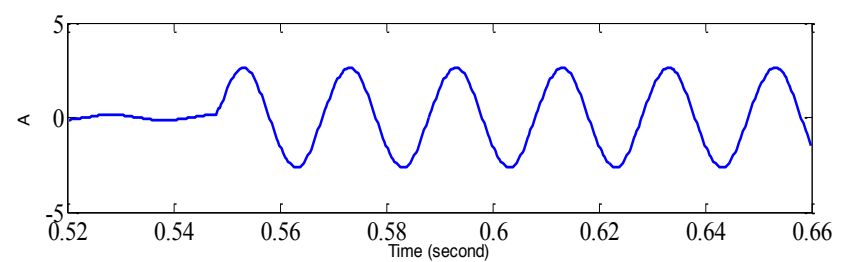

(a) Inception angle of 90 degrees.

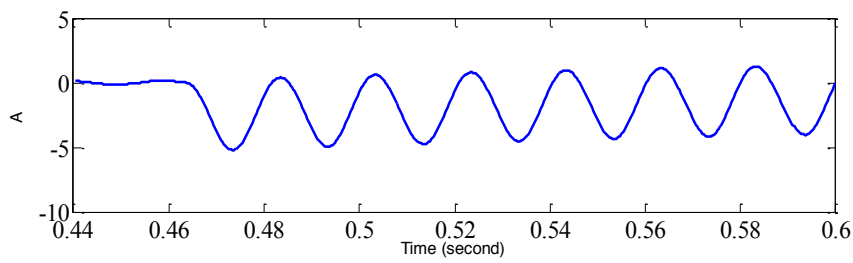

(b) Inception angle of 180 degrees.

Fig. 3. Current waveform captured from oscilloscope for various inception angles of fault in overhead line distribution system.

By changing only size of load and not for the length of $40 \%$ measured from the variable voltage transformer as shown in Table 2 and Figure 3, it can be seen that the obtained current is significantly increased both pre- and postfault condition with the increase of the size of load. This indicates that the fault detection decision algorithm will be beneficial. In addition, the maximum current during the prefault condition becomes higher with the increasing the size of load. By considering the data in Table 2, it can be seen that the fault current in case of size of load as non-linear load (combination between $25 \mathrm{~W}$ and ballast) is higher than the case of linear load. Moreover, the fault current is not affected with the increase of the size of load, but it was increased due to the voltage of variable voltage transformer adjusted to keep constant voltage of load as $220 \mathrm{~V}$. If the voltage of load was not adjusted at $220 \mathrm{~V}$, the size of load was minimally impacted.
Table 2. The maximum amplitude of current during pre- and post-fault condition for various loads in overhead line distribution system.

\begin{tabular}{|c|c|c|c|c|}
\hline \multirow{2}{*}{$\begin{array}{c}\text { Location of Fault } \\
\text { (\%length of } \\
\text { distribution system) }\end{array}$} & $\begin{array}{c}\text { Inception } \\
\text { angle }\end{array}$ & $\begin{array}{c}\text { Size of load } \\
(\mathrm{W})\end{array}$ & \multicolumn{2}{|c|}{$\begin{array}{c}\text { Maximum amplitude of current } \\
\text { (A) }\end{array}$} \\
\hline \multirow{4}{*}{40} & $90^{\circ}$ & 25 & 0.145 & 2.625 \\
\cline { 3 - 5 } & $90^{\circ}$ & 50 & 0.294 & 3.599 \\
\cline { 2 - 5 } & $90^{\circ}$ & 25+Ballast & 0.473 & 6.176 \\
\hline
\end{tabular}

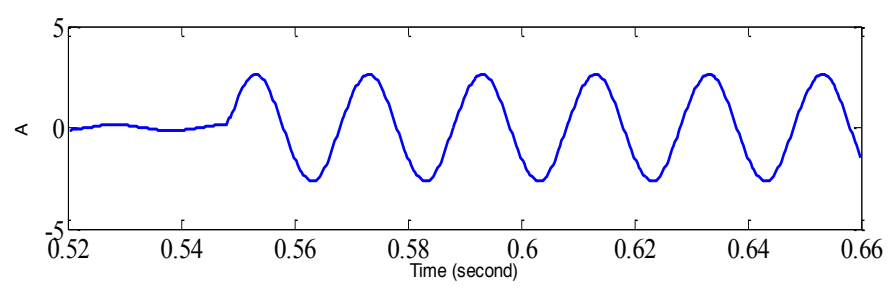

(a) Load of $25 \mathrm{~W}$.

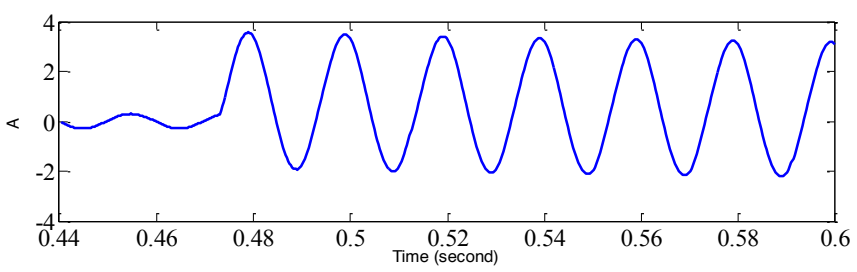

(b) Load of $50 \mathrm{~W}$.

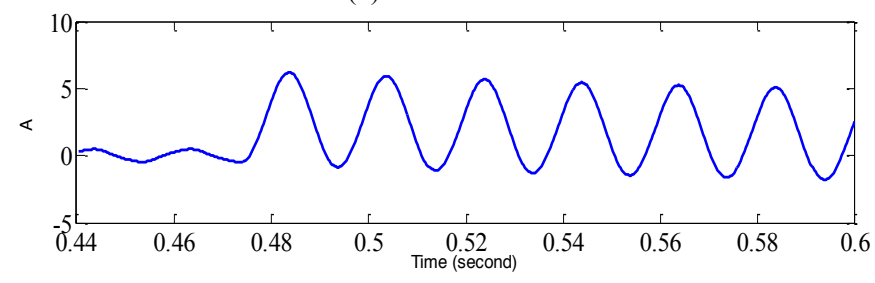

(c) Load of $25 \mathrm{~W}+$ Ballast.

Fig. 4. Current waveform captured from oscilloscope for various loads in overhead line distribution system.

By changing the location of fault and not for the inception angle set as $180^{\circ}$ and size of load is $25 \mathrm{~W}$ as shown in Table 3 and Figure 5, it can be seen that, during the postfault condition, the fault current tends to decrease with the increase of the distance between the fault point and variable voltage transformer due to the impedance of distribution line model tends to increase. To support this assertion, the location of fault as $40 \%$ of length distribution line has the same behavior as the case of the length of distribution line as $50 \%$ but the amplitude of fault current was higher than that the case of the length of distribution line as $50 \%$. 
Table 3. The maximum amplitude of current during pre- and post-fault condition for various fault locations along overhead line distribution system.

\begin{tabular}{|c|c|c|c|c|}
\hline \multirow{2}{*}{$\begin{array}{c}\text { Location of Fault } \\
\text { (\%length of } \\
\text { distribution system) }\end{array}$} & \multirow{2}{*}{$\begin{array}{l}\text { Inception } \\
\text { angle }\end{array}$} & \multirow{2}{*}{$\begin{array}{l}\text { Size of load } \\
\text { (W) }\end{array}$} & \multicolumn{2}{|c|}{$\begin{array}{l}\text { Maximum amplitude of } \\
\text { current (A) }\end{array}$} \\
\hline & & & Pre-fault & Post-fault \\
\hline 40 & $180^{\circ}$ & 25 & 0.145 & 2.625 \\
\hline 50 & $180^{\circ}$ & 25 & 0.145 & 2.026 \\
\hline 60 & $180^{\circ}$ & 25 & 0.145 & 1.499 \\
\hline
\end{tabular}

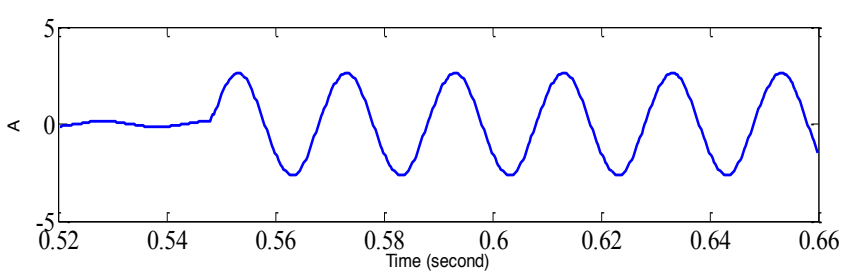

(a) $40 \%$ of cable's distance.

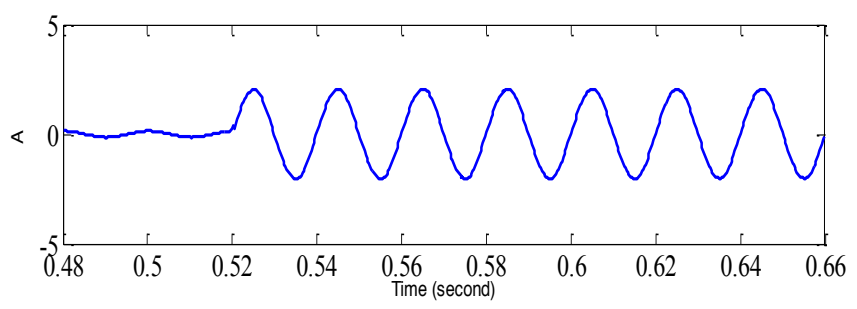

(b) $50 \%$ of cable's distance.

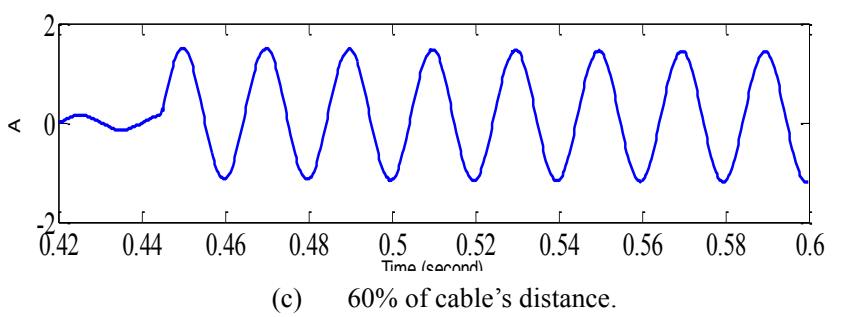

Fig. 5. Current waveform captured from oscilloscope for various fault locations along overhead line distribution system.

\subsection{Underground distribution system}

After analyzing the characteristics of fault current during the single-line to ground fault occurrence on the overhead line distribution system, in this section, the results in case of characteristics of fault current on underground cable distribution system were shown in Figures 6-8 and Tables 4-6.

By changing the inception angle of fault as shown in Table 4 and Figure 6, when fault occurs at the length of $40 \%$ measured from the variable voltage transformer while the load is $25 \mathrm{~W}$, it can be seen that, before the fault occurrence (or normal condition), the maximum amplitude of current is 0.153 A. During the fault occurrence (or fault condition) in case of the inception angle as $90^{\circ}$, the maximum amplitude of current changes suddenly on the waveform while the maximum amplitude of current is $3.078 \mathrm{~A}$. For the other inception angle of fault as shown in Figure 6(b), it can be seen that the maximum amplitude of current during fault occurrence has a value more than the case of the inception angle as $90^{\circ}$ while, during the normal condition, the maximum amplitude of current has the same value as the case of the inception angle of $90^{\circ}$ as shown in Table 4. As a result, this is the same behavior as the case of overhead line, but the amplitude of the fault current is more than the previous case.

Table 4. The maximum amplitude of current during pre- and post-fault condition for various inception angles of fault in underground cable distribution system.

\begin{tabular}{|c|c|c|c|c|}
\hline \multirow{2}{*}{$\begin{array}{c}\text { Location of Fault } \\
\text { (\%length of }\end{array}$} & $\begin{array}{c}\text { Inception } \\
\text { angle }\end{array}$ & $\begin{array}{c}\text { Size of load } \\
\text { distribution system) }\end{array}$ & \multicolumn{2}{|c|}{$\begin{array}{r}\text { Maximum amplitude of } \\
\text { current (A) }\end{array}$} \\
\cline { 4 - 5 } & & Pre-fault & Post-fault \\
\hline \multirow{2}{*}{40} & $90^{\circ}$ & 25 & 0.153 & 3.078 \\
\cline { 2 - 5 } & $180^{\circ}$ & 25 & 0.153 & 4.505 \\
\hline
\end{tabular}

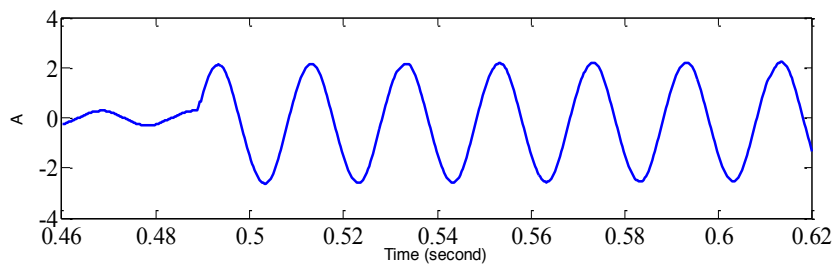

(a) 90 degrees.

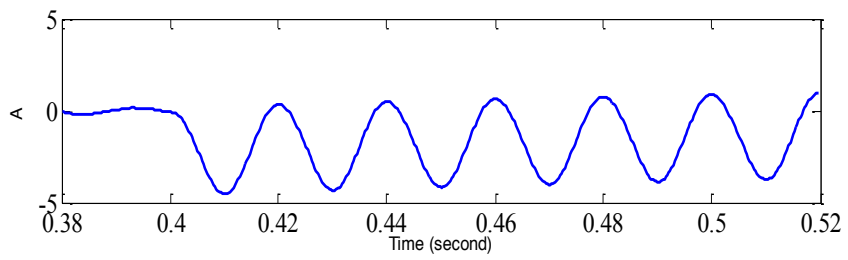

(b) 180 degrees.

Fig. 6. Current waveform captured from oscilloscope for various inception angles of fault in underground cable distribution system.

By changing only size of load and not for the length of $40 \%$ measured from the variable voltage transformer as shown in Table 5 and Figure 7, it can be seen that the obtained current is also significantly increased both pre- and post-fault condition with the increase of the size of load. By carefully considering the data in Table 2 , it can be seen that the fault current in case of non-linear load (combination between $25 \mathrm{~W}$ and ballast) is also higher than the case of linear load, but less than the case of overhead line, as previously mentioned. 
Table 5. The maximum amplitude of current during pre- and post-fault condition for various loads in underground cable distribution system.

\begin{tabular}{|c|c|c|c|c|}
\hline \multirow{2}{*}{$\begin{array}{c}\text { Location of Fault } \\
\text { (\%length of } \\
\text { distribution system) }\end{array}$} & $\begin{array}{c}\text { Inception } \\
\text { angle }\end{array}$ & Size of load & \multicolumn{2}{|c|}{$\begin{array}{c}\text { Maximum amplitude of current } \\
\text { (W) }\end{array}$} \\
\cline { 4 - 5 } & & & Pre-fault & Post-fault \\
\hline \multirow{4}{*}{40} & $90^{\circ}$ & 25 & 0.153 & 2.613 \\
\cline { 2 - 5 } & $90^{\circ}$ & 50 & 0.278 & 3.078 \\
\cline { 2 - 5 } & $90^{\circ}$ & 25+Ballast & 0.374 & 5.615 \\
\hline
\end{tabular}

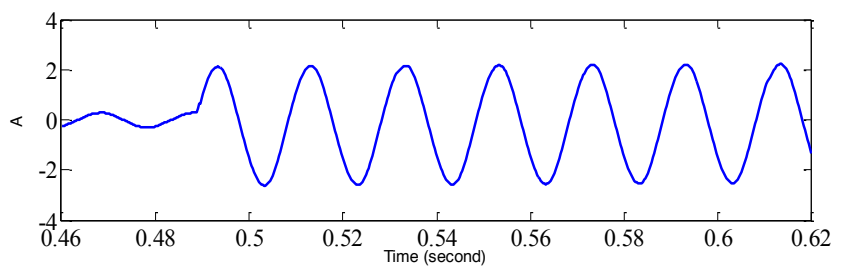

(a) Load of $25 \mathrm{~W}$.

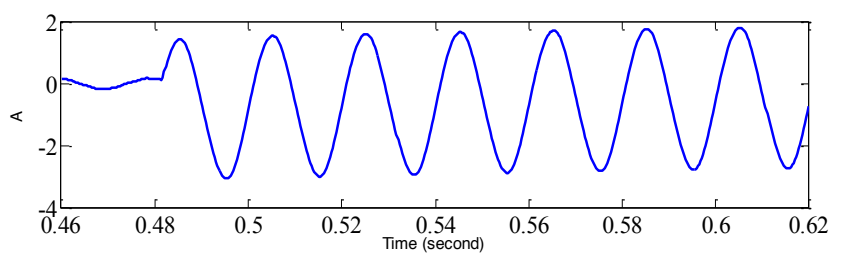

(b) Load of $50 \mathrm{~W}$.

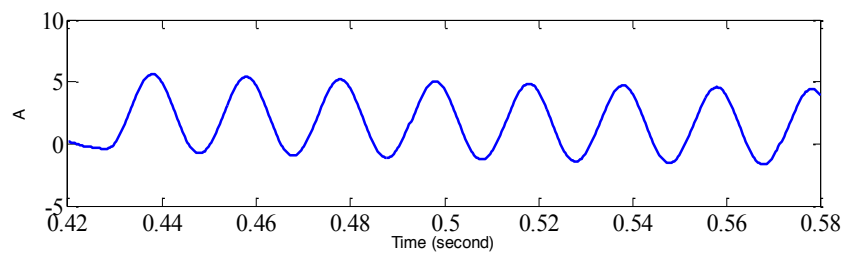

(c) Load of $25 \mathrm{~W}+$ Ballast.

Fig. 7. Current waveform captured from oscilloscope for various loads in underground cable distribution system.

By changing the location of fault and not for the inception angle of $180^{\circ}$ and size of load is $25 \mathrm{~W}$ as shown in Table 6 and Figure 8, it can be seen that, during the postfault condition, the fault current tends to decrease with the increase of the distance between the fault point and variable voltage transformer; this has also the same behavior as in the case of overhead line, but the amplitude of the fault current is more than the other case.

Table 6. The maximum amplitude of current during pre- and post-fault condition for various fault locations along underground cable distribution system.

\begin{tabular}{|c|c|c|c|c|}
\hline \multirow{2}{*}{$\begin{array}{c}\text { Location of Fault } \\
\text { (\%length of } \\
\text { distribution system) }\end{array}$} & \multirow{2}{*}{$\begin{array}{c}\text { Inception } \\
\text { angle }\end{array}$} & \multirow{2}{*}{$\begin{array}{c}\text { Size of load } \\
(\mathrm{W})\end{array}$} & $\begin{array}{c}\text { Maximum amplitude of current } \\
\text { (A) }\end{array}$ \\
\hline & $180^{\circ}$ & 25 & Pre-fault & Post-fault \\
\hline 40 & $180^{\circ}$ & 25 & 0.153 & 2.613 \\
\hline 50 & $180^{\circ}$ & 25 & 0.153 & 2.449 \\
\hline 60 & & & & \\
\hline
\end{tabular}

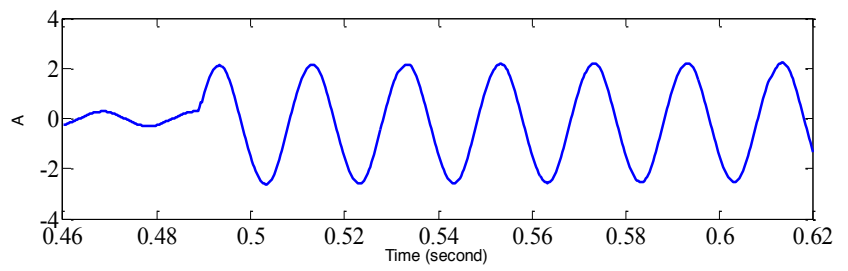

(a) $40 \%$ of cable's distance.

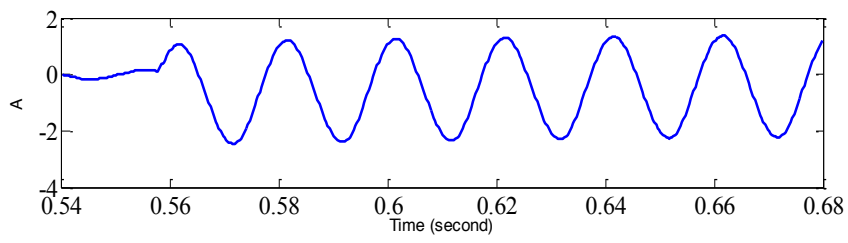

(b) $50 \%$ of cable's distance.

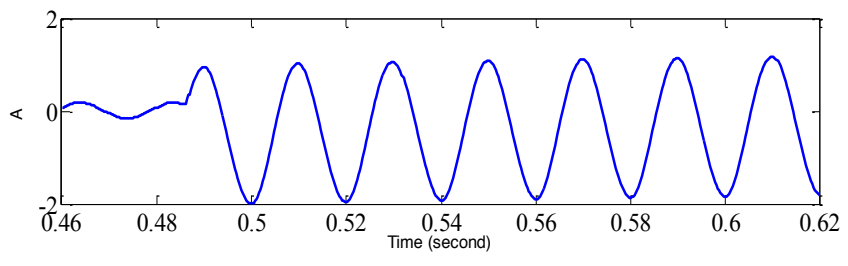

(c) $60 \%$ of cable's distance.

Fig. 8. Current waveform captured from oscilloscope for various fault locations along underground cable distribution system

\section{Conclusion}

This paper has focused on the characteristics of the single-line to ground fault current obtained from the experimental test bench. This experimental test bench calculated the parameter based on per-unit method by using the data from size of conductor, types of conductor, and configuration of distribution system so that the pi-lumped equivalent circuit can be achieved. The various case studies were performed with the type of distribution system, the location of fault, the inception angle of fault including varying the load. The result is summarized as follows:

- For the type of distribution system, the fault current during post-fault condition in case of overhead line is less than the case of underground cable.

- For the location of fault, the fault current during postfault condition tends to significantly decrease with the increase of fault distance between the fault point and variable voltage transformer.

- For the inception angle of fault, the fault current during post-fault condition in case of the inception angle of fault as $180^{\circ}$ has the amplitude of fault current more than the case of the inception angle of fault as $90^{\circ}$.

- For the size of load, the fault current during postfault condition is not affected with the increase of the size of load. 
Finally, the obtained results will be developed for the protective relay scheme. Further work will consider the AI algorithm to create the fault detection decision algorithm.

\section{ACKNOWLEDGMENT}

The authors wish to gratefully acknowledge financial support for this research (No. KREF025606) from the King Mongkut's Institute of Technology Ladkrabang Research fund, Thailand.

\section{REFERENCES}

[1] M. Jaya Bharata Reddy, D. Venkata Rajesh, Pathirikkat Gopakumar, and Dusmanta Kumar Mohanta, "Smart Fault Location for Smart Grid Operation Using RTUs and Computational Intelligence Techniques", IEEE Journal, Vol. 8, No. 4, pp. 1260-1271, December 2014.

[2] Tarlochan S. Sidhu and Zhihan Xu, "Detection of Incipient Faults in Distribution Underground Cables", IEEE Transactions, Vol. 25, No. 3, pp. 1363-1371, July 2010.

[3] Ke Meng, Zhao Yang Dong and Kit Po Wong, "Enhancing the Computing Efficiency of Power System Dynamic Analysis with
PSS_E” Proceedings of the 2009 IEEE International Conference, October 2009.

[4] Wenzhong Gao and Jiaxin Ning, "Wavelet-Based Disturbance Analysis for Power System Wide-Area Monitoring", IEEE transactions, Vol. 2, No. 1, pp. 121-130, March 2011.

[5] N. Perera, and A. D. Rajapakse,"Recognition of Fault Transients Using a Probabilistic Neural-Network Classifier", IEEE transactions, Vol. 26, No. 1, pp. 410-419, January 2011.

[6] Solak, Waldemar Rebizant and Andrzej (Andrew) Klimek Krzysztof, "Fuzzy Adaptive Transmission-Line Differential Relay Immune to CT Saturation", IEEE transactions, Vol. 27, No. 2, pp. 766-772, April 2012.

[7] Meisam Pourahmadi-Nakhli and Ali Akbar Safavi , "Path Characteristic Frequency-Based Fault Locating in Radial Distribution Systems Using Wavelets and Neural Networks", IEEE transactions, Vol. 26, No. 2, pp. 772-781, April 2011.

[8] Carlos Frederico, M. Almeida and Nelson Kagan, "Using Genetic Algorithms and Fuzzy Programming to Monitor Voltage Sags and Swells", IEEE transactions, Vol. 26, pp. 46-53, April 2011. 